\title{
Effect of Vascular Endothelial Growth Factor on Maturation, Fertilization and Developmental Competence of Bovine Oocytes
}

\author{
Hailing $\mathrm{LUO}^{1,2) * *}$, Koji KIMURA ${ }^{2)}$, Mari $\mathrm{AOKI}^{2)}$ and Makoto HIRAKO ${ }^{2) *}$ \\ ${ }^{1)}$ Animal Science Department, Gansu Agricultural University, Lanzhou 730070, China and ${ }^{2)}$ Department of Grazing Animal Production, \\ National Grassland Research Institute, Nishinasuno, Tochigi 329-2793, Japan
}

(Received 9 October 2001/Accepted 20 May 2002)

ABSTRACT. To examine the effect of Vascular Endothelial Growth Factor (VEGF) on the maturation of bovine oocytes, human recombinant $\mathrm{VEGF}_{165}$ was used in 3 experiments. In Exp. 1, bovine cumulus oocyte complexes (COCs) were matured for $22 \mathrm{hr}$ in modified Synthetic Oviduct Fluid (m-SOF) supplemented with 0 (control) or $5 n \mathrm{~g} / \mathrm{m} l$ of VEGF. Maturation rate increased $(\mathrm{P}<0.05)$ from $78.2 \%$ in the control to $90.5 \%$ in the VEGF treated group. In Exp. 2, bovine COCs were matured in $\mathrm{m}$-SOF and co-incubated with sperm in modified BO medium, each supplemented with or without $5 \mathrm{ng} / \mathrm{m} l$ VEGF. Normal fertilization rate was improved (P<0.05) from $63.0 \%$ (control) to $79.8 \%$ or $82.3 \%$ with VEGF during maturation or both maturation and fertilization. In Exp. 3, bovine COCs were matured the same way as in Exp. 1, then co-incubated with sperm for $6 \mathrm{hr}$ and cultured for $162 \mathrm{hr}$ in m-SOF without VEGF. Cleavage rate and development rate to the 4- to 8-cell stage were examined at $42 \mathrm{hr}$ post-co-incubation and development rate to blastocyst was examined at $162 \mathrm{hr}$ post-co-incubation. Cleavage, the development to the 4 - to 8 -cell stage and blastocyst rates $(82.0 \%, 70.3 \%$ and $45.1 \%$, respectively) were significantly higher $(\mathrm{P}<0.05)$ in the VEGF group than those in the control $(67.3 \%, 52.5 \%$ and $33.3 \%$, respectively). These results indicate that VEGF has a beneficial effect on the maturation of bovine oocytes.

KEY WORDS: bovine oocyte, early embryonic development, fertilization, maturation, Vascular Endothelial Growth Factor. J. Vet. Med. Sci. 64(9): 803-806, 2002

In the mammalian reproductive system, the oviduct provides an optimal microenvironment for the development of the zygote. Oviductal fluid influences final oocyte-maturation, sperm capacitation, fertilization and early embryonic development. The composition and the amount of fluid produced by the bovine oviduct change according to the stage of the estrous cycle, with more fluid at estrus and ovulation $[5,13]$. The oviduct secretes many growth promoting factors, such as Fibroblast Growth Factor (FGF), Epidermal Growth Factor (EGF), Transforming Growth Factor (TGF) $\beta 1$, Vascular Endothelial Growth Factor (VEGF) and others [12]. Expression of these growth factors differs between animal species [15].

VEGF is known as a potent mitogen for micro- and macro-vascular endothelial cells [7, 17] and as a stimulator of vascular permeability based on its ability to induce vascular leakage $[2-4,20]$. It is essential for the development of follicles and corpora lutea in the ovary, and the establishment of vascular structure in the placenta [8]. The expression of VEGF is correlated with vascularization of tissues during the female reproductive cycle including embryogenesis $[18,21]$.

Gabler et al. [10, 11] suggested that VEGF might be involved in creating an optimal local environment for fertilization and/or early embryonic development by modulating permeability in the bovine oviduct. Einspanier et al. [6]

\footnotetext{
* Correspondence to: Hirako, M., Department of Animal Breeding and Reproduction, National Institute of Livestock and Grassland Science, Nishinasuno, Tochigi 329-2793, Japan.

**Present address: Luo, H., Department of Animal Production, College of Animal Science and Technology, China Agricultural University, Beijing 100094, China.
}

found that VEGF transcripts increased continuously in bovine granulosa cells accompanied by follicular development and the concentration of VEGF in follicular fluid was 5 -fold higher in preovulatory follicles $(5 \mathrm{ng} / \mathrm{ml})$ compared with early antral follicles $(1 \mathrm{ng} / \mathrm{ml})$. These findings suggest that VEGF is involved in the maturation of oocytes or the early development of embryos in cattle. The aim of this study was to investigate the effect of VEGF on maturation of bovine oocytes in vitro.

\section{MATERIALS AND METHODS}

Reagents: Human recombinant $\mathrm{VEGF}_{165}$ derived from Sf21 insect cells was obtained from R\&D systems (Minneapolis, MN, U.S.A.) and utilized at $5 \mathrm{ng} / \mathrm{ml}$. For in vitro culture of bovine oocytes and embryos, Synthetic Oviduct Fluid (SOF) [22] was supplemented with $1 \%$ basal medium Eagle-essential amino acid (BME-EAA, Sigma B-6766, St. Louis, MO, U.S.A.), $1 \%$ minimum essential medium-nonessential amino acid (MEM-NEAA, Sigma M-7145), $5 \mathrm{mM}$ taurine (Sigma T-7146), $0.5 \mathrm{mM}$ pyruvic acid (Sigma P4562), $100 \mathrm{UI} / \mathrm{m} l$ penicillin (Sigma Pen-K) and $100 \mu \mathrm{g} / \mathrm{m} l$ streptomycin (Meiji Seika, Tokyo, Japan). For in vitro fertilization, BO medium [1] was supplemented with $20 \mu \mathrm{g} / \mathrm{m} l$ heparin (Sigma H-3149) and $3 \mathrm{mg} / \mathrm{m} l$ fatty acid-free bovine serum albumin (BSA, Sigma A-7511).

In vitro maturation (IVM): Bovine ovaries were obtained at a local abattoir and transported to the laboratory in physiological saline $\left(30-35^{\circ} \mathrm{C}\right)$ within $5 \mathrm{hr}$. Follicular contents were aspirated from small antral follicles $(2-5 \mathrm{~mm})$ using an 20 -gauge needle attached to a $10 \mathrm{~m} l$ disposable syringe, then allowed to settle in a Petri dish and the supernatant was dis- 
carded. Only cumulus oocyte complexes (COCs) with multilayered compact cumulus cells were selected for maturation in vitro. The COCs were washed 3 times with SOF containing 10\% Fetal Bovine Serum (FBS, ICN Biomedical Inc., Aurora, OH, U.S.A.), $1.5 \mathrm{mM}$ glucose (Dextrose anhydrous, Wako Pure Chemical Industries, Osaka, Japan), $2 \mu \mathrm{g} / \mathrm{m} l$ Follicle Stimulating Hormone (FSH, Antrin, Denka Pharamaceutical, Kawasaki, Japan), $2 \mu \mathrm{g} / \mathrm{m} l$ estradiol-17 $\beta$ (Sigma E-1127). Groups of $20 \pm 2$ COCs were matured in $100 \mu \mathrm{l}$ droplets of the same medium under paraffin oil for $22 \mathrm{hr}$ at $39^{\circ} \mathrm{C}$ in an atmosphere of $5 \% \mathrm{CO}_{2}$ in air.

In vitro fertilization (IVF): After IVM, COCs were washed 3 to 4 times with BO medium and transferred in groups of $20 \pm 2$ to $100 \mu \mathrm{l}$ fertilization droplets of the same medium under paraffin oil. For the capacitation of spermatozoa, frozen-thawed $\left(37^{\circ} \mathrm{C}\right)$ Japanese Black semen was layered on 45 and $60 \%$ discontinuous Percoll (Amersham Pharmacia Biotech, Piscataway, NJ, U.S.A.) gradient BO medium and centrifuged $15 \mathrm{~min}$ at $800 \times \mathrm{g}, 37^{\circ} \mathrm{C}$. The sperms were diluted to a final concentration of $5 \times 10^{6}$ sperms $/ \mathrm{ml}$. Gametes were co-incubated for $6 \mathrm{hr}$ in BO medium under paraffin oil at $39^{\circ} \mathrm{C}$ in an atmosphere of $5 \%$ $\mathrm{CO}_{2}$ in air.

In vitro culture (IVC): The presumptive embryos were washed 3 to 4 times with SOF supplemented with $1 \%$ FBS following IVF, then placed $20 \pm 2$ embryos in a $100 \mu l$ droplet of the same medium under paraffin oil and cultured at $39^{\circ} \mathrm{C}$ in an atmosphere of $5 \% \mathrm{CO}_{2}, 5 \% \mathrm{O}_{2}, 90 \% \mathrm{~N}_{2}$ until 42 hr post-co-incubation. Then, cumulus cells surrounding the embryos were removed gently by a suitable glass pipette. The denuded embryos were washed 3 to 4 times with SOF supplemented with 5\% FBS, then transferred in groups of 20 \pm 2 to $30 \mu \mathrm{l}$ droplet of the same medium under paraffin oil and cultured under the same conditions as the preceding culture for $120 \mathrm{hr}$.

Exp. 1. Effect of VEGF on maturation of bovine oocytes: The effect of VEGF on maturation was assessed by the maturation rate at $22 \mathrm{hr}$ of IVM in medium supplemented with or without VEGF. The oocyte was fixed for $90 \mathrm{hr}$ in a fixative (glacial acetic acid: ethanol, 1: 3), stained with $1 \%$ aceto-orcein ( $1 \%$ orcein in $45 \%$ acetic acid), preserved with acetoglycerol solution (glacial acetic acid: glycerin: $\mathrm{H}_{2} \mathrm{O}, 1$ : 1:3) and evaluated microscopically. Oocytes at metaphaseII were considered to have matured.

Exp. 2. Effect of VEGF on fertilization of bovine oocytes. The effect of VEGF on fertilization was assessed by penetration and fertilization rates after $10 \mathrm{hr}$ of co-incubation with sperms. The COCs were matured in vitro with or without VEGF, then co-incubated with or without VEGF. The oocytes were fixed for $80 \mathrm{hr}$, stained, preserved and evaluated microscopically. The oocytes with one male and one female pronuclei and one sperm tail in the ooplasma were considered to have been fertilized normally.

Exp. 3. Effect of VEGF on developmental competence of bovine oocytes: IVM of bovine oocytes was performed with or without VEGF the same as in Exp. 1. IVF and IVC were performed without VEGF. The cleavage rate and development rate at the 4- to 8-cell stage were assessed at $42 \mathrm{hr}$ postco-incubation. The development rate to the blastocyst was examined at $162 \mathrm{hr}$ post-co-incubation.

Statistical analysis: Data are presented as percentages or means with standard errors. Repeated measures of one-way ANOVA were carried out in Exp. 1 and 3. The results of Exp. 2 were subjected to repeated measures of two-way ANOVA. Differences were considered to be significant at $\mathrm{P}<0.05$

\section{RESULTS}

In Exp. 1, a total of 260 bovine oocytes were examined for the maturation rate in 7 replicates. VEGF significantly increased the maturation rate of the oocytes compared with the control (Table 1).

In Exp. 2, 462 oocytes were examined in 7 replicates. As shown in Tables 2 and 3, the maturation, penetration and fertilization rates were significantly increased when the oocytes were matured with VEGF. However, the effect of VEGF supplement during insemination on these rates was not significant $(\mathrm{P}>0.05)$. There was no significant interaction between groups supplemented with VEGF during maturation and insemination (Table 3 ).

In Exp. 3, in 6 replicates, 225 oocytes were examined. As shown in Table 4, VEGF added to the maturation medium significantly enhanced the cleavage rate, and the development rates up to the 4- to 8-cell stage and the blastocyst. However, the development rate from the 4- to 8-cell stage to the blastocyst in the group with VEGF was similar $(\mathrm{P}>0.05)$ to the control.

\section{DISCUSSION}

Many published reports have dealt with the effect of growth factors on mammalian oocytes [19], but the effect of VEGF on oocyte maturation has not been reported. The results of the present study demonstrate that VEGF increased $(\mathrm{P}<0.05)$ the maturation (Exp. 1 and 2$)$, penetration and fertilization rates (Exp. 2) of bovine oocytes. The cleavage, the development rates from the oocyte to the 4- to 8 -cell stage and the blastocyst were higher $(\mathrm{P}<0.05)$ in the group with VEGF than the control (Exp. 3). However, the development rate from the 4- to 8-cell stage embryo to the blastocyst stage were similar $(\mathrm{P}>0.05)$ in both VEGF and

Table 1. Effect of VEGF on nuclear maturation of bovine oocytes cultured in modified SOF

\begin{tabular}{cccc}
\hline Treatment & $\begin{array}{c}\text { No. of } \\
\text { replicates }\end{array}$ & $\begin{array}{c}\text { No. of oocytes } \\
\text { examined }\end{array}$ & $\begin{array}{c}\text { No. of matured } \\
\text { oocytes }(\% \pm \text { SEM) }\end{array}$ \\
\hline- & 7 & 126 & $98(78.2 \pm 4.7)^{\mathrm{a})}$ \\
+ & 7 & 134 & $121(90.5 \pm 2.2)^{\mathrm{b}}$ \\
\hline
\end{tabular}

+: matured with $5 \mathrm{ng} / \mathrm{m} l$ VEGF; -: matured without VEGF.

a,b) Values in the same column with different superscripts differ significantly $(\mathrm{P}<0.05)$. 
Table 2. Effect of VEGF on fertilization of bovine oocytes matured and fertilized in vitro

\begin{tabular}{ccccrcc}
\hline \multicolumn{2}{c}{ Treatment } & \multirow{2}{*}{ No. of } & \multirow{2}{*}{ No. of oocytes } & \multicolumn{3}{c}{ No. of oocytes (\% \pm SEM) } \\
\cline { 5 - 7 } M & F & replicates & examined & Metaphase-II & penetrated & fertilized normally \\
\hline- & - & 7 & 120 & $101(84.2 \pm 2.4)$ & $78(65.6 \pm 5.8)$ & $75(63.0 \pm 6.0)$ \\
- & + & 7 & 118 & $100(84.6 \pm 2.5)$ & $91(77.0 \pm 4.7)$ & $88(74.5 \pm 6.2)$ \\
+ & - & 7 & 109 & $99(90.5 \pm 3.1)$ & $89(81.8 \pm 3.7)$ & $87(79.8 \pm 4.5)$ \\
+ & + & 7 & 115 & $105(91.1 \pm 1.9)$ & $98(85.0 \pm 2.8)$ & $95(82.3 \pm 3.6)$ \\
\hline
\end{tabular}

M: IVM; F: IVF; +: With 5 ng/ml VEGF; -: Without VEGF.

Table 3. Significance (P value) in statistical analyses of data in Table 2 by two-way ANOVA

\begin{tabular}{lccc}
\hline Period & Metaphase-II & Penetrated & Fertilized normally \\
\hline Maturation & $\mathbf{0 . 0 2}$ & $\mathbf{0 . 0 1}$ & $\mathbf{0 . 0 3}$ \\
Fertilization & 0.86 & 0.11 & 0.20 \\
Interaction & 0.96 & 0.34 & 0.41 \\
\hline
\end{tabular}

Table 4. Effect of VEGF on the developmental competence of bovine embryos produced in vitro*

\begin{tabular}{cccccc}
\hline Treatment & $\begin{array}{c}\text { No.of } \\
\text { replicates }\end{array}$ & $\begin{array}{c}\text { No.of oocytes } \\
\text { examined }\end{array}$ & \multicolumn{3}{c}{ No. (\% \pm SEM) of oocytes developed to } \\
\cline { 4 - 6 } & 6 & 114 & $77(67.3 \pm 5.2)^{\mathrm{a})}$ & $60(52.5 \pm 6.3)^{\mathrm{a})}$ & $38(33.3 \pm 3.2)^{\mathrm{a})}$ \\
+ & 6 & 111 & $91(82.0 \pm 2.3)^{\mathrm{b})}$ & $78(70.3 \pm 3.6)^{\mathrm{b})}$ & $50(45.1 \pm 2.0)^{\mathrm{b})}$ \\
\hline & & & &
\end{tabular}

control groups. Therefore, the improved development rate from the oocyte to the blastocyst was observed in more of the 4- to 8-cell stage embryos obtained from the group supplemented with VEGF during maturation. These results indicate that VEGF added to the culture medium during IVM enhances the developmental competence of mammalian oocytes.

The first polar body formation and the fertilization rates of oocytes matured in vitro are generally lower than those of oocytes matured in vivo [23]. This difference is attributed to incomplete cytoplasmic maturation in vitro [9]. In the present study, the maturation rate was comparatively higher when bovine COCs were cultured with VEGF. This result suggests that VEGF promotes nuclear maturation. Furthermore, since the cumulus mass expanded well in the group with VEGF, the VEGF-induced nuclear maturation might be mediated by cumulus cells similar to the effect of other growth factors, such as EGF [16]. However, as observed in a previous study [14], EGF does not promote the proportion of normally fertilized oocytes (oocytes with one sperm tail, one male and one female pronuclei) after co-incubation. In Exp. 2 of the present study, the penetration and normal fertilization rates of bovine oocytes were significantly higher $(\mathrm{P}<0.05)$ in VEGF groups than those in the control when the oocytes were treated with $5 \mathrm{ng} / \mathrm{m} l$ VEGF during maturation or during maturation and fertilization. Furthermore, the subsequent development of bovine oocytes matured with
VEGF was improved in Exp. 3. These results suggest that VEGF induces cytoplasmic maturation as well as nuclear maturation in bovine oocytes.

Hainaut et al. [14] postulated that the effect of IGF-I on maturation is initiated upon activation of the membrane receptor for this growth factor and requires tyrosine dephosphorylation of $\mathrm{p} 34$, the kinase component of Maturation Promoting Factor. It was not clear from this experiment whether VEGF had an effect on the oocyte directly or indirectly via cumulus cells. The mechanism of the effect of VEGF on the maturation of bovine oocytes seems complex compared with IGF-I and further study will be necessary for its elucidation.

In conclusion, VEGF stimulated the maturation of bovine oocytes in vitro, resulting in promotion of the normal fertilization rate and the subsequent development of fertilized oocytes. We therefore suggest that VEGF is an important factor not only for nuclear maturation but also for cytoplasmic maturation of bovine follicular oocytes.

\section{REFERENCES}

1. Brackett, B. G. and Oliphant, G. 1975. Capacitation of rabbit spermatozoa in vitro. Biol. Reprod. 12: 260-274.

2. Connolly, D. T. 1991. Vascular permeability factor: a unique regulator of blood vessel function. J. Cell. Biochem. 47: 219223.

3. Connolly, D. T., Heuvelman, D. M., Nelson, R., Olander, J. V., 
Eppley, B. L., Delfino, J. J., Siegel, N. R., Leimgruber, R. M. and Feder, J. 1989. Tumor vascular permeability factor stimulates endothelial cell growth and angiogenesis. J. Clin. Invest. 84: $1470-1478$.

4. Connolly, D. T., Olander, J. V., Heuvelman, D., Nelson, R., Monsell, R., Siegel, N., Haymore, B. L., Leimgruber, R. M. and Feder, J. 1989. Human vascular permeability factor. Isolation from U937 cells. J. Biol. Chem. 264: 20017-20024.

5. Ehrenwald, E., Foote, R. H. and Parks, J. E. 1990. Bovine oviductal fluid components and their potential role in sperm cholesterol efflux. Mol. Reprod. Dev. 25: 195-204.

6. Einspanier, R., Muller, K., Bieser, B., Kosmann, M. and Schams, D. 1999. Differential expression of VEGF in bovine ovarian follicles and first effect of VEGF applied during in vitro maturation of oocytes. J. Reprod. Fertil. (Abstract series) 23: 7.

7. Ferrara, N. and Davis-Smyth, T. 1997. The biology of vascular endothelial growth factor. Endocr. Rev. 18: 4-25.

8. Findlay, J. K. 1986. Angiogenesis in reproductive tissues. $J$. Endocrinol. 111: 357-366.

9. First, N. L. and Barnes, F. L. 1989. Development of preimplantation mammalian embryos. Prog. Clin. Biol. Res. 294: 151170.

10. Gabler, C., Einspanier, A., Schams, D. and Einspanier, R. 1999. Expression of vascular endothelial growth factor (VEGF) and its corresponding receptors (flt-1 and flk-1) in the bovine oviduct. Mol. Reprod. Dev. 53: 376-383.

11. Gabler, C., Schams, D, Einspanier, A. and Einspanier, R. 1996. VEGF, TGF-alpha, TGF-beta in the bovine oviduct and indication of their regulation during the estrous cycle. Arch. Tierzucht. (SPEC. ISSUE) 39: 29.

12. Gandolfi, F., Brevini, T. A. L., Modina, S., Bianchi, R. and Passoni, L. 1993. Role of the oviduct during early embryogenesis. Reprod. Domest. Anim. 28: 189-192.

13. Gerena, R. L. and Killian, G. J. 1990. Electrophoretic characterization of proteins in oviduct fluid of cows during the estrous cycle. J. Exp. Zool. 256: 113-120.

14. Hainaut, P., Giorgetti, S., Kowlaski, A., Ballotti, R. and Van
Obberghen, E. 1991. Antibodies to phosphotyrosine injected to xenopus laevis oocytes modulate maturation induced by insulin/IGF-I. Exp. Cell Res. 195: 129-136.

15. Heyner, S., Shan, N., Smith, R. M., Watson, A. J. and Schultz, G. A. 1993. The role of growth factors in embryo production. Theriogenology 39: 151-161.

16. Im, K. S. and Park, K.W. 1995. Effects of epidermal growth factor on maturation, fertilization and development of bovine follicular oocytes. Theriogenology 44: 209-214.

17. Leung, D. W., Cachianes, G., Kuang, W. J., Goeddel, D. V. and Ferrara, N. 1989. Vascular endothelial growth factor is a secreted angiogenic mitogen. Science 246: 1306-1309.

18. Millauer, B., Wizigmann-Voos, S., Schnurch, H., Martinez, R., Moller, N. P. H., Risau, W. and Ullrich, A. 1993. High affinity VEGF binding and developmental expression suggest flk-1 as a major regulator of vasculogenesis and angiogenesis. Cell 72: 835-846.

19. Park, K. W., Iga, K. and Niwa, K. 1997. Exposure of bovine oocytes to EGF during maturation allows them to development blastocysts in a chemically-defined medium. Theriogenology 48: 1127-1135.

20. Senger, D. R., Galli, S. J., Dvorak, A. M., Perruzzi, C. A., Harvey, V. S. and Dvorak, H. F. 1983. Tumor cells secrete a vascular permeability factor that promotes accumulation of ascites fluid. Science 219: 983-985.

21. Shweiki, D., Itin, A., Neufeld, G., Gitay-Goren, H. and Keshet, E. 1993. Patterns of expression of vascular endothelial growth factor (VEGF) and VEGF receptors in mice suggest a role in hormonally regulated angiogenesis. J. Clin. Invest. 91: 22352243.

22. Tervit, H. R., Whittingham, D. G. and Rowson, L. E. A. 1972. Successful culture in vitro of sheep and cattle ova. J. Reprod. Fertil. 30: 493-497.

23. Trounson, A. O., Willadsen, S. M. and Rowson, L. E. A. 1977. Fertilization and development capability of bovine follicular oocytes matured in vitro and in vivo and transferred to the oviducts of rabbits and cows. J. Reprod. Fertil. 51: 321-327 